\title{
Percepção de alunos do Ensino Médio de uma escola pública do interior de Minas Gerais quanto ao uso de anabolizantes
}

\author{
Perception of high school students from a public school in the \\ interior of Minas Gerais regarding the use of anabolic steroids \\ Percepción de estudiantes de secundaria de una escuela pública del \\ interior de Minas Gerais sobre el uso de esteroides anabólicos
}

\author{
Leandro Martins Ramos (leandromartinslm331@gmail.com) \\ Faculdade Cidade de Coromandel - FCC. \\ Douglas Pereira Castro (mscdouglascastro@ hotmail. Com) \\ Professor da Faculdade Cidade de Coromandel - FCC.
}

Resumo: A busca dos jovens pelo corpo perfeito influi para o consumo de esteroides anabólicos androgênicos (EAA), entretanto o consumo desses sem prescrição médica pode acarretar efeitos colaterais graves. O objetivo do estudo foi averiguar $\mathrm{O}$ conhecimento de adolescentes do Ensino Médio de uma escola pública sobre os EAA. Selecionou-se 31 alunos entre 15 e 17 anos ( 17 homens e 14 mulheres). O instrumento utilizado se tratou de um questionário. A maioria dos alunos não havia utilizado EAA e sabiam dos possíveis efeitos colaterais $(90,3 \%)$, dos que usaram os meios foram: injetáveis $(3,2 \%)$, ingestão $(3,2 \%)$ e ambas $(3,2 \%)$. Acerca da tratativa do assunto em casa $60 \%$ responderam de forma negativa. Todos os alunos disseram conhecer sobre os EAA. Sobre a indicação dos EAA a outra pessoa, 3\% responderam de forma afirmativa, enquanto $97 \%$ não indicariam o uso. Diante do uso por motivos estéticos $16 \%$ relataram o interesse e $84 \%$ responderam que não usariam. Em relação à abordagem em sala de aula $58 \%$ afirmaram terem tido aulas a esse respeito e $90 \%$ julgam necessário à presença do assunto na grade curricular. Conclui-se então a relevância da atuação docente na abordagem sobre os EAA em sala de aula.

Palavras-chave: Esteroides; adolescentes; professores.

\begin{abstract}
The search of young people for the perfect body influences the consumption of anabolic androgenic steroids (AAS), however the consumption of these without a medical prescription can cause serious side effects. The objective of the study was to ascertain the knowledge of high school adolescents in a public school about AAS. 31 students between 15 and 17 years old (17 men and 14 women) were selected. The instrument used was a questionnaire. Most students had not used AAS and were aware of the possible side effects $(90.3 \%)$, of those who used the means were: injectable
\end{abstract}

Recebido em: 05/02/2021

Aceite em: 13/09/2021 
(3.2\%), intake $(3.2 \%)$ and both $(3.2 \%)$. Regarding the treatment of the matter at home, $60 \%$ answered in the negative. All students said they knew about EAA. Regarding the indication of AAS to another person, 3\% responded in the affirmative, while $97 \%$ would not indicate the use. When using it for aesthetic reasons, $16 \%$ reported interest and $84 \%$ replied that they would not use it. Regarding the approach in the classroom, $58 \%$ said they had taken classes in this regard and $90 \%$ considered it necessary for the subject to be included in the curriculum. The relevance of teaching performance in the approach to AAS in the classroom is therefore concluded.

Keywords: Steroids; Adolescents; Teachers.

Resumen: La búsqueda de los jóvenes por el cuerpo perfecto influye en el consumo de esteroides anabólicos androgénicos (AAS), sin embargo el consumo de estos sin prescripción médica puede ocasionar efectos secundarios graves. El objetivo del estudio fue conocer el conocimiento de adolescentes de secundaria en una escuela pública sobre AAS. Se seleccionaron 31 estudiantes entre 15 y 17 años (17 hombres y 14 mujeres). El instrumento utilizado fue un cuestionario. La mayoría de los estudiantes no habían utilizado AAS y eran conscientes de los posibles efectos secundarios (90,3\%), de los que utilizaron los medios fueron: inyectables $(3,2 \%)$, ingesta $(3,2 \%)$ y ambos $(3,2 \%))$. En cuanto al tratamiento del asunto en casa, el $60 \%$ respondió negativamente. Todos los estudiantes dijeron que sabían sobre EAA. En cuanto a la indicación de AAS a otra persona, el 3\% respondió afirmativamente, mientras que el $97 \%$ no indicaría el uso. Al usarlo por razones estéticas, el 16\% manifestó interés y el $84 \%$ respondió que no lo usaría. En cuanto al abordaje en el aula, el 58\% dijo haber tomado clases al respecto y el $90 \%$ consideró necesario que la asignatura se incluya en el plan de estudios. Por tanto, se concluye la relevancia del desempeño docente en el abordaje de la EAA en el aula.

Palabras-clave: Esteroides; Adolescentes; Profesores.

\section{INTRODUÇÃO}

\subsection{CONCEITUAÇÕES DOS ESTEROIDES ANABOLIZANTES} ANDRÓGENOS

Os Esteroides Anabolizantes Andrógenos (EAA) são de uma família de hormônios similares à testosterona, que apresentam duas formas de ações em indivíduos que os consomem, conhecidas como: andrógenas e anabólicas. A ação andrógena está relacionada com mudanças como queima maior de tecido adiposo e aumento de massa magra, tanto no corpo masculino quanto no feminino, enquanto a ação anabólica compreende a hipertrofia muscular e o aumento da síntese proteica (SANTOS 2003).

Recebido em: 05/02/2021

Aceite em: 13/09/2021 
Os efeitos desejáveis da utilização associam-se diretamente com a maior produção de proteínas pelas células, com a redução da fadiga muscular e o aumento da retenção de glicogênio intracelular, favorecendo o metabolismo dos aminoácidos e a inibição do cortisol, a utilização destas substâncias tende a suprimir o sistema imunológico tornando os indivíduos mais propensos a desenvolverem gripes e resfriados (OLIVEIRA, 2012).

Os EAA em geral são sintetizados a partir da testosterona que se trata do hormônio sexual masculino mais potente. Ao longo dos anos, as pesquisas apontam contribuições significativas mediante o tratamento à base desse composto para a regressão da incapacidade funcional, ressalta-se ainda a atuação desses para a melhora do desempenho em atividades aeróbicas e facilita a recuperação em exercícios excessivos (DIAS, 2014).

A relação direta do uso dos EAA com a eficiência nas atividades aeróbicas vincula-se a um aumento na produção de hemácias o que leva ao aumento da capacidade respiratória do indivíduo, podendo assim, haver a potencialização na taxa de gordura corporal queimada (OLIVEIRA, 2012).

De acordo com o Conselho Nacional de Antidopagem (CNAD, 2004) anabolizantes são substâncias que favorecem a hipertrofia muscular, promovendo um ganho maior do que o corpo consegue chegar apenas com treinamento. Tais substâncias apresentam a função de auxiliar o organismo a sintetizar mais rapidamente as fibras musculares após as lesões, além de realizar a renovação de outras células promovendo uma rápida recuperação do corpo.

As definições sobre os EAA devem ser tratadas de maneira profunda nos ambientes educacionais, pois, o conhecimento acerca das funções e os mecanismos de atuação por parte deles podem colaborar para uma redução do uso por parte de crianças e adolescentes.

\subsection{RISCOS DECORRENTES DO USO DE EAA.}

Os riscos existentes devido ao uso dos EAA sem uma consulta médica são abordados por Souza e Fisberg (2002). Os autores descrevem os possíveis efeitos 
colaterais de ordem clínica e psíquica, podendo acarretar uma indissociabilidade do indivíduo, inclusive no âmbito escolar, podendo gerar reações desrespeitosas aos colegas e aos professores.

Brito e Faro (2017) mencionam que o uso indevido dos EAA tanto para homens quanto para mulheres pode causar danos muitas vezes irreversíveis. O autor aponta ainda o risco de infecção pelo vírus HIV, no uso das substâncias injetáveis, onde podese haver um compartilhamento de agulhas para a aplicação dos anabolizantes.

O uso abusivo dos anabolizantes provocam distúrbios comportamentais, endócrinos, cardiovasculares, hepáticos e musculoesqueléticos. De acordo com Varella (2011) são divididos em grupos e respectivamente classificados como: distúrbios comportamentais, endócrinos, cardiovasculares, hepáticos e musculoesqueléticos.

Os distúrbios comportamentais incluem agressividade e irritabilidade, apontamentos indicam que a inconstância das emoções em geral é observada por euforia transitória presentes no início do uso dos EAAs, seguida por aumento da ansiedade e da condição de ira caracterizada pela raiva generalizada em usuários frequentes. Fatores como o aumento ou diminuição do apetite sexual, transtornos bipolares, síndrome do pânico, quadros depressivos podem ser associados ao uso frequente dos esteroides (HALL, 2005; VARELLA, 2011).

A utilização dos EAAs está diretamente relacionada a alterações endócrinas adjuntas ao aparecimento de acnes, perda da libido, impotência sexual, diminuição de esperma ejaculado, ginecomastia, irregularidade menstrual, engrossamento da voz, pelos indesejados no corpo, dificuldade de fixação do embrião ao útero, diabetes, entre outros (IRIART, et al. 2009; CUNHA, et al. 2004).

Acerca dos efeitos colaterais cardíacos a literatura traz que, possíveis alterações no metabolismo do colesterol podem levar a doenças coronarianas graves em usuários recorrentes de EAAs, isso se dá através do aumento do colesterol (LDL) e a diminuição do (HDL). A hipertensão arterial também se associa ao uso de EAAs, estes colaboram para a retenção de líquidos pelo organismo (HARTGENS, et al. 2004; RIBEIRO, 2001).

O relato de mortes de indivíduos jovem em decorrência a problemas cardíacos são cada vez mais frequentes na literatura, um dos motivadores desses óbitos são os Recebido em: 05/02/2021

Aceite em: 13/09/2021 
EAAs, estes apresentam toxicidade que podem provocar lesões ao tecido cardíaco, induzindo assim uma cardiopatia que pode prejudicar a sístole e a diástole, bem como a disfunção ventricular (DE SIQUEIRA NOGUEIRA, 2014).

Os distúrbios hepáticos provocados pela administração de EAA estão associados diretamente à estrutura e fisiologia do fígado. As células responsáveis pelo metabolismo desses compostos podem entrar em colapso. As principais alterações encontradas a partir dessa situação são: icterícia, peliose hepática, hiperplasia hepatocelular. Disfunções enzimáticas também podem ser observadas, o aumento da aspartatoaminotransferase, da aldolase, da transamina glutamil oxidade (TGO) e da transamina glutamil peroxidase (TGP) são recorrentes. As taxas de ocorrência dos problemas relatados aumentam a partir da duração do uso da droga. (BOFF, 2010).

Os distúrbios musculoesqueléticos se associam a lesões por solicitações exageradas (overuse), fechamento das epífises ósseas precocemente e consequentemente o retardamento no crescimento ósseo de todo corpo. O apontamento dos riscos, quando bem trabalhado, apresenta efeitos importantes para a diminuição da cultura do corpo perfeito a qualquer custo (VARELLA, 2011).

Devido aos diferentes efeitos colaterais apresentados pelo uso indiscriminado de EAA, a atuação dos profissionais da saúde e da educação deve ser frequente e adquirir um caráter transversal, tendo vista a mitigação das enfermidades e problemas decorrentes do uso dessas substâncias.

\subsection{RELAÇÃO DOS ADOLESCENTES QUANTO AO USO DE EAA}

Não se pode falar de adolescência sem abordar o corpo, e não se pode abordar o corpo dissociando-o da mente. Desta forma as alterações físicas decorrentes dessa idade induzem o processo de desenvolvimento psicossocial de formação do sujeito. A formulação de uma identidade neste estágio da vida, necessariamente, envolve tratativas acerca do corpo (CANO, 1999).

A imagem corporal precede a adolescência, mas nessa fase ela passa por uma reafirmação na qual envolve um processo construtivista de experiências vividas sejam elas reais ou utópicas. Seguindo essa perspectiva o adolescente por vezes apresenta uma

Recebido em: 05/02/2021

Aceite em: 13/09/2021 
dificuldade de aceitação das modificações ocorridas, levando assim a uma sensação de não pertencimento e estranheza de si. A imagem corporal é construída por diferentes percepções e emoções, que podem ser mutáveis perante variáveis como as experiências físicas e ambientais (OLIVEIRA, 2012).

A Sociedade Brasileira de Endocrinologia e Metabologia (SBEM, 2016) relata que o uso de anabolizantes entre os estudantes do ensino médio teve um crescimento de $67 \%$, sendo que entre os alunos matriculados no terceiro ano o aumento foi de $84 \%$. Nota-se que nas duas últimas décadas a procura por EAA entre os jovens tem aumentado significativamente.

Costa et al. (2007) relacionam o uso dos anabolizantes entre os jovens em alta escala e grandes doses com o objetivo de melhoramento estético e aperfeiçoamento do vigor físico. Isso ocorre pelo desconhecimento dos malefícios ao longo dos anos do uso de tais substâncias.

Ribeiro (2001) acusa a mídia televisa como uma das maiores influências no consumo dos anabolizantes relata ainda que a insatisfação dos jovens com a aparência física pode gerar a baixa autoestima. $\mathrm{O}$ autor coloca em voga a pressão social, onde a sociedade valoriza um corpo esbelto e com bom desempenho em áreas esportivas, inclusive na escola onde o esporte deveria ser um referencial de socialização, respeito, educação. Dentre outros valores, percebe-se que em geral a competitividade e o resultado ainda se destacam entre os professores de Educação Física. Em linhas gerais a sociedade moderna valoriza em grande parte quesitos estéticos. Dessa forma, um físico avantajado é almejado por grande parte dos adolescentes, perfazendo assim um importante grupo de risco para o consumo indiscriminado dos EAA.

Nessa perspectiva Araújo (2003) menciona em sua pesquisa realizada em uma escola pública de Brasília que 5,5\% dos adolescentes disseram ter realizado o consumo de anabolizantes. A maioria revelou que a indicação partiu de amigos.

Os adolescentes fazem parte de um grupo de risco para o consumo de diversos compostos químicos, entre eles os EAA. Isso pode ter relação ao período de inconstância emocional vivido por eles. Dessa forma, é imprescindível o apoio a tais sujeitos por diferentes segmentos da sociedade.

Recebido em: 05/02/2021

Aceite em: 13/09/2021 


\subsection{ATUAÇÃO DO PROFESSOR DE EDUCAÇÃO FÍSICA FRENTE AOS} RISCOS DO USO DE EAA

A escola é identificada como uns locais de aprendizagem, dessa maneira tais instituições são de sobremaneira responsáveis pelo levantamento de informações acerca de temáticas variadas, inclusive aquelas relacionadas a saúde dos seus alunos. Nesse contexto os educandários favorecem a identificação da prevalência de fatores de risco e dessa forma apresenta subsídios primordiais para a aplicação de políticas públicas de saúde que envolva tanto a prevenção quanto à promoção de saúde (FUMAGALLI et al. 2019).

Nesse viés o papel do professor de Educação Física nas escolas está associado a variável saúde, este profissional necessita desnudar aspectos relacionados ao conceito de esporte vinculado a saúde. A mídia em geral associa a imagem do professor a uma figura responsável pela manutenção dos hábitos saudáveis dos alunos, isso se torna incoerente a partir do momento que a mesma mídia induz principalmente aos jovens a cultura do corpo perfeito. Desta forma cabe ao professor se posicionar e através de ferramentas transdisciplinares buscarem saídas para que a informação chegue corretamente aos discentes (DARIDO, et al. 2012).

As orientações Curriculares aos Parâmetros Curriculares Nacionais (BRASIL, 2002), discorrem que a disciplina de Educação Física escolar deve tratar os aspectos relacionados à cultura corporal. Segundo o documento é necessário transpor a perspectiva de simples hora de lazer e esporte "constituindo-se como um trabalho que tematiza a cultura corporal, encarada como linguagem".

A partir dessa perspectiva o desígnio da disciplina está enviesado na busca pela interação crítica do aluno na esfera da cultura corporal, e para a efetividade dessa ação torna-se fundamental que as aulas forneçam aos alunos, informações relevantes e contextualizadas sobre todos os prismas relacionados à cultura do corpo. Cabe ao professor manter o diálogo crítico com as mídias, executando momentos reflexivos durante as aulas, para que os discentes possam adquirir autonomia em suas ações para além dos muros das escolas (ANJOS, 2014).

Segundo o autor anteriormente citado o Conteúdo Básico Comum da Educação Física trata o tema saúde de forma rápida, associando a mesma a uma perspectiva Recebido em: 05/02/2021

Aceite em: $13 / 09 / 2021$ 
histórica, permeada ao corpo em movimento e com a atividade física. Na sequência integra a saúde com qualidade de vida, que corresponde a várias dimensões como: biológica, psicológica, social, cultural econômica e ambiental. Não há maiores citações sobre o tema ao longo do texto, apenas compõe as habilidades e competências a serem desenvolvidas.

De acordo com os Currículos Básicos Comuns (CBC) o Eixo temático "Esporte" indica que sejam realizadas explicações sobre o tema saúde "a apresentação dos efeitos do doping no organismo e seus malefícios para a saúde; a relação entre esporte, consumo e mídia, a compreensão da relação entre mídia, indústria esportiva, consumo e a análise da influência dos meios de comunicação nas práticas esportivas" (SECRETARIA DE ESTADO DA EDUCAÇÃO DE MINAS GERAIS, 2005, p. 56).

No eixo temático "Ginástica" está disposto: "Análise das razões e das implicações do uso de anabolizantes para a obtenção do corpo ideal"; "Análise dos padrões de corpo impostos pela cultura" (SECRETARIA DE ESTADO DA EDUCAÇÃO DE MINAS GERAIS, 2005, p.61).

Em consonância a essa abordagem percebe-se que o número de usuários de EAA entre os adolescentes vem aumentando e o âmbito escolar tornou-se um ambiente onde isso se torna mais notório, sendo que a intervenção dos docentes se faz mais necessária. Entre as drogas utilizadas por esses escolares os anabolizantes têm papel de destaque (SILVA, 2014).

O autor supracitado destaque ainda que o professor de Educação Física tem um papel fundamental na formação dos alunos, não só em questões físicas, mas também com o objetivo de instruir os indivíduos sobre os riscos do uso de drogas, incluindo os EAA. A Educação Física contribui na sensibilização do aluno desde a infância, retratando que uma vida saudável só é possível através de práticas diárias efetivas.

Canavez (2017) relata que a inserção da temática de prevenção ao uso de drogas na grade curricular torna-se uma das alternativas de maior alcance ao público adolescente, promovendo, dessa forma, uma conscientização quanto aos riscos do uso de tais substâncias. Segundo o autor o trabalho de sensibilização é algo que deve acontecer em longo prazo, na tentativa de disseminação da temática também entre as crianças.

Recebido em: 05/02/2021

Aceite em: 13/09/2021 
Em relação às estratégias educacionais para conter o abuso de drogas, nota-se que, na percepção coletiva é fundamental a existência de ações cujo caráter seja preventivo e que estas sejam desenvolvidas por professores dos Ensinos Fundamental e Médio (ARMELIN, 1999).

Ferreira et al. (2010) ressaltam uma postura variável por parte do professor quanto a abordagem do uso de drogas, uma vez que nem todos os docentes se veem com o papel de mediador de tais problemas sociais ou se encontram com algum receio quanto a inserção do tema 'drogas' nas aulas. É possível encontrar profissionais da educação que se preocupam com tal problema público, que inserem o tema em suas aulas após notar indícios de uso das referidas substâncias por algum aluno presente em sala.

Somente através de uma boa relação entre o professor e os alunos situações adversas pode ser convertidas em um diálogo aberto, nesse contexto de troca o professor exerce um papel central para a sensibilização do jovem, fato que se torna mais brando e significativo a partir do instante em que é alcançado mais afinidade entre ambos (OSORIO VELOSO, L.; SOARES, R.; COPETTI, J, 2020).

Ademais a atuação dos docentes deve ser contínua e sistematizada, a temática referente aos diferentes categorias de drogas deve ser caracterizada de forma interdisciplinar e transdisciplinar durante todo o ano letivo. Enfatiza-se o papel do professor de Educação Física no enfrentamento do aumento do uso de EAA pelos adolescentes. O estudo objetivou averiguar a percepção de alunos matriculados no ensino médio de uma escola pública localizada em um município no interior de Minas Gerais em relação aos anabolizantes esteroides.

\section{METODOLOGIA}

A presente pesquisa teve natureza analítica, quantitativa do tipo descritiva seguindo à metodologia adaptada de Araújo (2003) e foi desenvolvida na Escola Estadual "Pedro Álvares Cabral", localizada no município de Abadia dos Dourados, no interior de Minas Gerais. A amostra foi obtida a partir de técnica de amostragem aleatória simples, para tal foi realizado um sorteio dos alunos matriculados nos $3^{\circ}$ anos do ensino médio da instituição alvo.

Recebido em: 05/02/2021

Aceite em: 13/09/2021 
O estudo teve autorização do Comitê de Ética em Pesquisas com seres humanos da Faculdade Patos de Minas sob o número: 2.439.202. Os participantes da pesquisa foram autorizados a fazer parte da mesma após a assinatura dos Termos de Consentimento Livre e Esclarecido (TCLE) pelos seus responsáveis legais. Ressalta-se que cada participante da pesquisa fez a assinatura do Termo de Assentimento.

O instrumento para realização da pesquisa deu-se a partir de um questionário estruturado com questões relacionadas ao tema proposto, com o intuito de averiguar o conhecimento dos alunos sobre o uso dos EAA. Os dados colhidos foram tabulados através do programa SPSS.

\section{RESULTADOS E DISCUSSÕES}

Diante da análise dos dados o gênero dos participantes construiu-se a Tabela 1.

Tabela 1 - Relação de gênero dos participantes

\begin{tabular}{ccc}
\hline Sianânerocientian & $\%$ \\
\hline Masculino & 17 & $\mathbf{5 5}$ \\
Feminino & 14 & 45 \\
\hline Total & 31 & $\mathbf{1 0 0}$ \\
\hline
\end{tabular}

Fonte: Autores, 2020.

Participaram da pesquisa 31 alunos do ensino médio, matriculados no ano de 2017. Percebeu-se que a amostra selecionada continha $55 \%$ de alunos do sexo masculino e $45 \%$ do sexo feminino.

Acerca da idade dos participantes da amostra observaram-se os valores descritos na Tabela 2.

Recebido em: 05/02/2021

Aceite em: 13/09/2021 
Tabela 2 - Idade dos alunos participantes

\begin{tabular}{ccl}
\hline Idade & n & $\%$ \\
\hline 15 & 6 & 19.3 \\
16 & 7 & 22.5 \\
17 & 18 & 58 \\
\hline Total & 31 & 100 \\
\hline
\end{tabular}

Fonte: Autores, 2020.

A pesquisa foi proposta ao ensino médio. Portanto, a tabela acima mostra a relação das idades dos participantes que foram 19,3\% com 15 anos, 22,5\% com 16 anos e 58\% com 17 anos. Em estudo realizado na cidade de Belo Horizonte por Ribeiro (1999) os adolescentes com faixa etária entre 15 e 18 são os maiores usuários de EAA. Já no trabalho semelhante realizado por Inácio et al. (2008) a maior parte dos usuários de EAA tinham entre 15 e 21 anos. Assim, o estudo com adolescentes se torna uma ferramenta ideal para a inserção do assunto e mitigação de futuros problemas de saúde pública.

Com base no nível de escolaridade dos pais o presente estudo compôs os dados descritos na Tabela 3.

Tabela 3 - Nível de escolaridade dos pais dos participantes

\begin{tabular}{lclll}
\hline Nível de escolaridade & Mãe & \% & Pai & \% \\
\hline Ensino fundamental incompleto & 9 & 29 & 10 & 32,3 \\
Ensino fundamental completo & 3 & 9,7 & 1 & 3,2 \\
Ensino médio incompleto & 7 & 22,5 & 3 & 9,7 \\
Ensino médio completo & 6 & 19,4 & 12 & 38,7 \\
Ensino superior incompleto & 2 & 6,5 & 1 & 3,2 \\
Ensino superior completo & 4 & 12,9 & 2 & 6,5 \\
Outros & - & - & 2 & 6,5 \\
\hline Total & $\mathbf{3 1}$ & $\mathbf{1 0 0}$ & $\mathbf{3 1}$ & $\mathbf{1 0 0}$ \\
\hline
\end{tabular}

Fonte: Autores, 2020. 
A pesquisa mostrou que $29 \%$ das mães apresentam o ensino fundamental incompleto, $9,7 \%$ com o ensino fundamental completo, $22,6 \%$ disseram que suas mães têm ensino médio incompleto, 19,4 possuem o ensino médio completo, $6,5 \%$ não terminaram o ensino superior e 12,9 concluíram o ensino superior. Quanto à relação de escolaridade dos pais, 32,3\% não terminaram o ensino fundamental, enquanto 3,2\% têm o ensino fundamental completo. Já o ensino médio 9,7\% não conseguiu terminá-lo, enquanto $38,7 \%$ o possuem completo, no ensino superior 3,2\% não concluíram e $6,5 \%$ são graduandos em um curso superior, enquanto 6,5\% dos pais dos alunos entrevistados possuem outro nível de escolaridade diferente dos citados acima.

Colocando em relação ao trabalho de Gonzaga (2012) os dados colhidos mostram uma distorção. Enquanto Gonzaga relatou que $45 \%$ dos pais dos entrevistados possuem o ensino fundamental, o levantamento realizado apontou $22,6 \%$ com o ensino médio, entretanto incompleto.

Quando perguntados sobre a abordagem do assunto em casa à amostra se comportou como exposto na Figura 1.

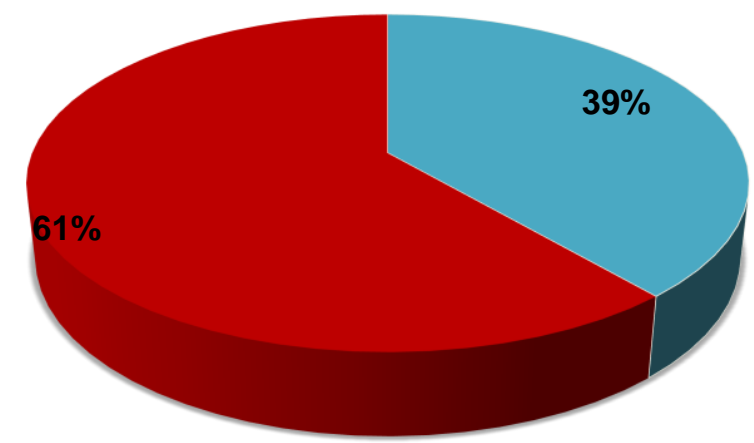

- $\operatorname{Sim}$ Não

Fonte: Autores, 2020.

Recebido em: 05/02/2021

Aceite em: 13/09/2021 
Figura 1 - Abordagem do assunto sobre EAA em casa

Segundo o levantamento sobre o tema EAA ser abordado nas casas dos participantes $61 \%$ desses respondeu de forma negativa. Tal fato enfatiza o papel da escola em propor medidas que abarquem as tratativas acerca dos anabolizantes, pois, nesses educandários as informações podem ser trabalhadas de forma científica, apontando os possíveis efeitos colaterais decorrentes do uso dessas substâncias.

Seguindo a perspectiva da orientação dos adolescentes, a pesquisa realizada por Malbegier et al. (2012) retratou a importância das ações conjuntas entre família, escola e profissionais da saúde para que jovens não recorram ao uso de drogas lícitas ou ilícitas, esta situação deve acontecer segundo o autor, através de um processo de sensibilização elencando os malefícios causados pelo uso das mesmas.

No que diz respeito às respostas dos adolescentes sobre onde possivelmente teriam ouvido sobre o tema os dados compõem a Figura 2.

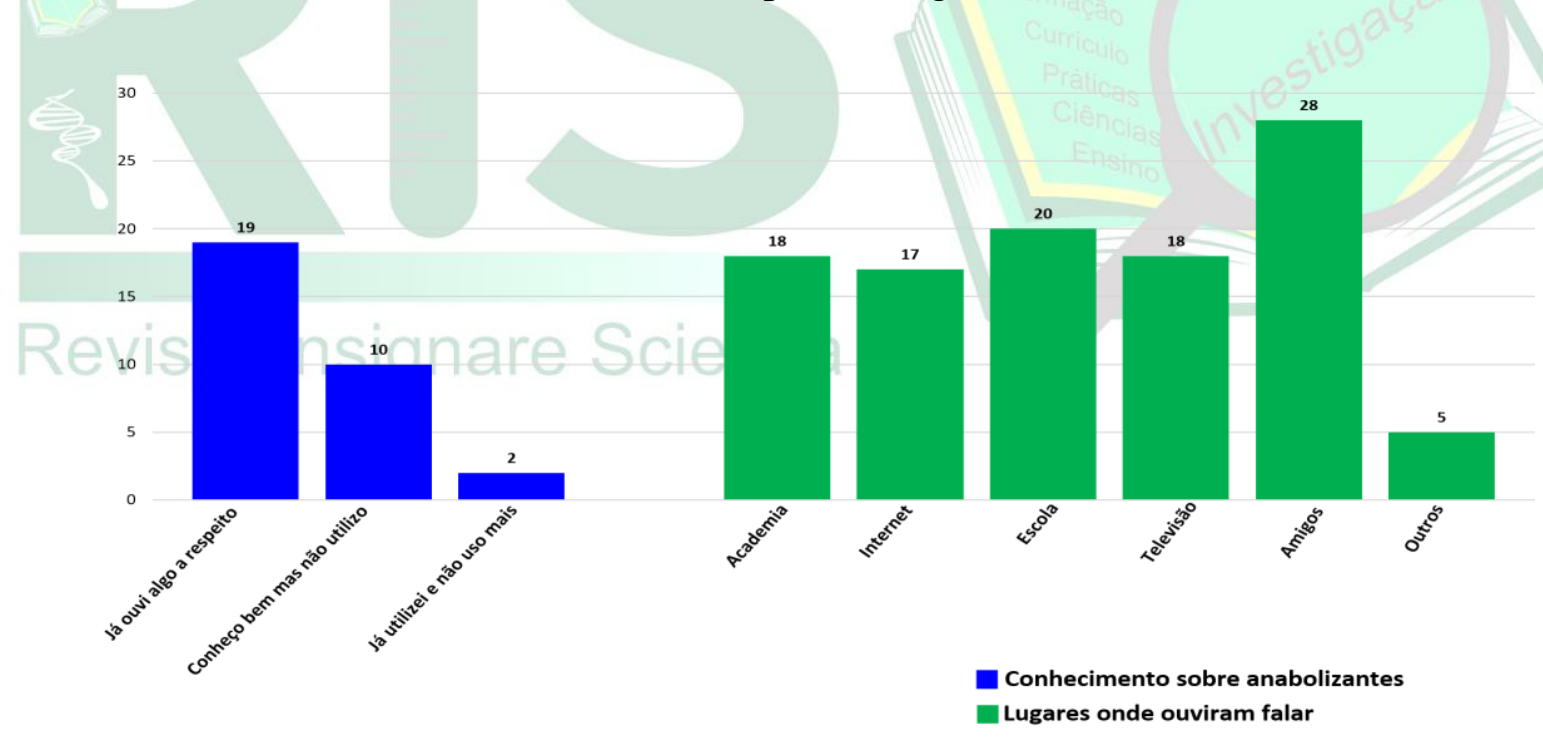

Fonte: Autores, 2020.

Figura 2 - Relação dos participantes que ouviram algo a respeito e supostos lugares onde ouviram

Quanto ao conhecimento dos EAA 62\% relataram ter ouvido algo a respeito, $32 \%$ conhecem bem, mas não utilizam e $6 \%$ relataram o consumo, entretanto não usam mais. Dos que já ouviram sobre o assunto 58\% relataram ser em academias, $54 \%$ na Recebido em: 05/02/2021

Aceite em: 13/09/2021 
internet, 64,5\% na escola, 58\% na mídia televisiva. Já 90\% dos pesquisados relacionam os amigos como meio intermediador e $16 \%$ disseram ter ouvido em outros lugares.

A presente pesquisa discorda do trabalho de Gonzaga (2012) no que se refere ao principal espaço em que os adolescentes tiveram acesso a informações relativas aos EAA, no estudo realizado pelo autor verificou-se que a maior parte da amostra estudada disse ter ouvido falar sobre anabolizantes na mídia televisa.

Em contraponto ao estudo de Gonzaga (2012), o trabalho de Carreira Filho (2005) realizado em uma escola de São Caetano do Sul, aponta que a mídia televisiva não exerce uma influência de fato aos níveis de conhecimento acerca dos EAAs.

A figura 3 traz as respostas dos entrevistados quando perguntados sobre o consumo ou não dos EAAs, abarca também de onde ou quem partiu a oferta dessa substância e por fim se conhecem ou não os efeitos colaterais provocados por estas substâncias.

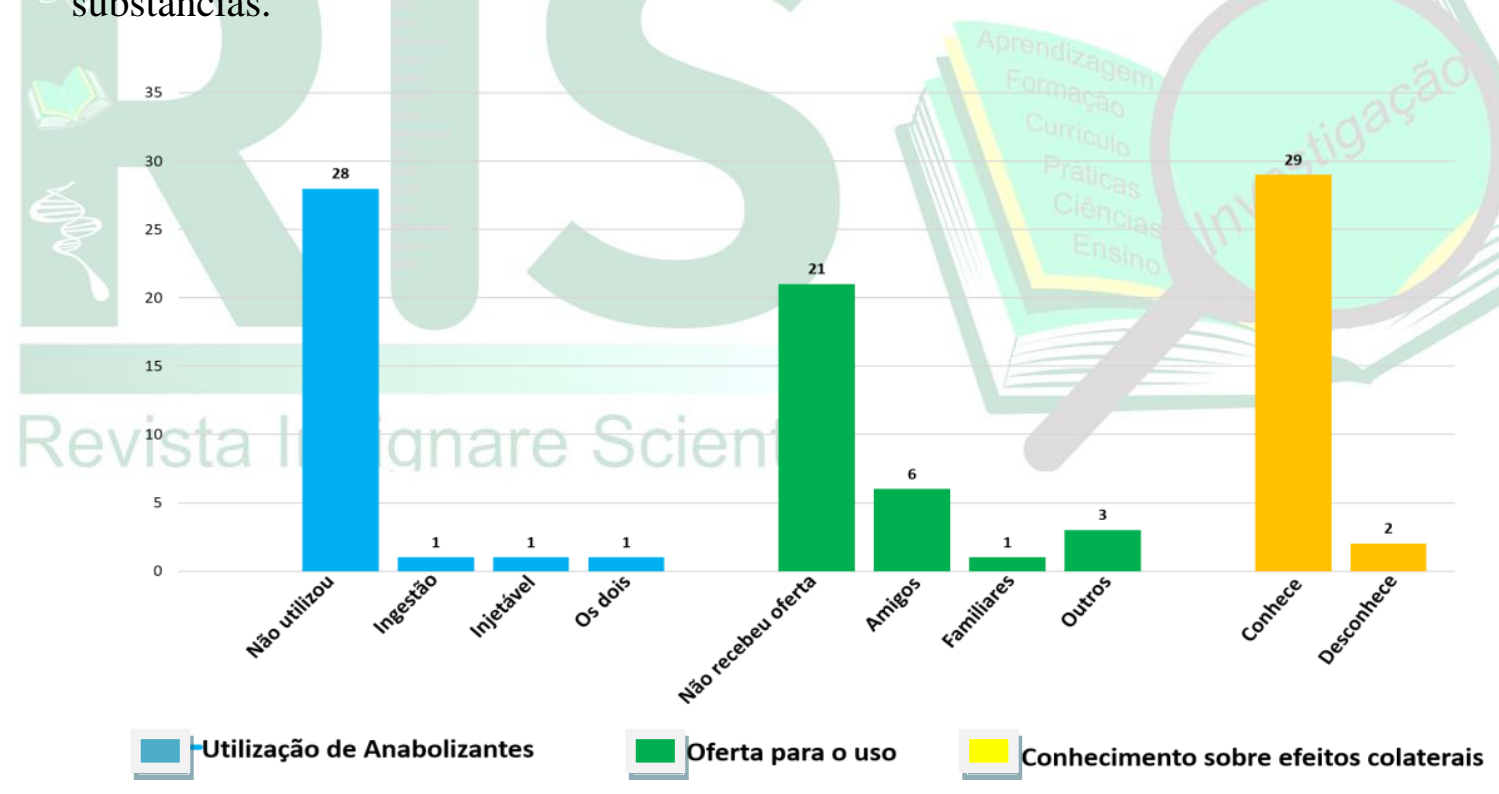

Fonte: Autores, 2020.

Figura 3 - Utilização de anabolizantes, oferta para o uso e conhecimento de efeitos colaterais.

Em relação ao uso de EAA 90,3\% relataram não ter feito utilização, enquanto 9,6\% disseram ter utilizado, a maneira que essas substâncias foram utilizadas se deram pode diferentes práticas sendo: por meio de injetáveis $(3,2 \%)$, por ingestão $(3,2 \%)$ e pelas duas formas $(3,2 \%)$. 
Com base nos dados encontrados na presente pesquisa, os achados de Dias (2014) diferenciam-se no que diz respeito a porcentagem de alunos que já realizaram o consumo de EAAs, na obra em questão $32 \%$ dos adolescentes já haviam consumido tais substâncias.

No que se refere a como esses sujeitos receberam a oferta para o uso, 19,3\% disseram que receberam oferta dos amigos, 3,2\% por familiares, 9,6\% receberam oferta por outras pessoas e 67,7\% não lhes foram ofertadas. Enquanto 93,5\% conhece algum efeito colateral provocado pelo uso de anabolizantes $6,5 \%$ desconhece qualquer efeito colateral relacionado ao uso do mesmo.

De acordo com a pesquisa de Araújo (2003), desenvolvida em escolas particulares e públicas de Brasília, 26\% dos participantes receberam a oferta para o uso, enquanto o presente estudo apresenta resultados contrários. Nota-se que na pesquisa apresentada 32,2\% dos estudantes já receberam alguma proposta para o consumo de tais substâncias. Entretanto, os dois trabalhos relacionam a maior oferta sugerida pelos amigos. Quanto aos efeitos colaterais, o trabalho realizado em Brasília apontou que $87,86 \%$ são conhecedores sobre algum efeito colateral provocado pelos anabolizantes, enquanto essa pesquisa mostrou 93,5\% também são cientes de tais efeitos.

Em trabalho similar Carreira Filho (2005) observou que indivíduos que utilizaram esteroides anabolizantes apresentaram a porcentagem de 2,39\% e declararam terem usado de tais substâncias com a finalidade de alteração corporal. Sendo que $3,78 \%$ para o sexo masculino e $0,96 \%$ para os sujeitos do sexo feminino, não existindo diferenças estatisticamente significantes entre os sexos.

No trabalho de Araújo (2003) quando perguntado aos participantes quem sugeriu o uso dos EAA 60,4\% relataram a indicação de um amigo. Um fato relevante foi que $26,57 \%$ receberam a sugestão de um professor. Ressalta-se que tal atitude por parte de um docente é considerada crime pelo conselho (CONFEF, 2003).

Sobre a indicação do uso para outras pessoas segue os dados disponíveis na Tabela 4.

Tabela 4 - Indicação para utilização de EAA e utilização para fins estéticos 


\begin{tabular}{clcl}
\hline Indicaria o uso & Sim & 1 & 3 \\
& Não & 30 & 97 \\
& Total & 31 & 100 \\
\hline Utilizaria por questão estética & Sim & 5 & 16 \\
& Não & 26 & 84 \\
& Total & 31 & 100 \\
\hline
\end{tabular}

Fonte: Autores, 2020.

Quanto à resposta sobre a indicação ao uso $3 \%$ responderam de forma afirmativa, enquanto $97 \%$ não indicariam o uso de anabolizantes. A respeito da utilização por motivos estéticos $16 \%$ relataram ter o interesse em usar e $84 \%$ disseram que não usariam por tais motivos, como propõe a tabela a seguir.

Os resultados do presente artigo discordam com aqueles apresentados por Araújo (2003) quanto à indicação para o uso dos EAAs, enquanto na pesquisa atual apenas 3\% indicariam o uso das substâncias, no estudo realizado por Araújo (2003) $24,88 \%$ dos entrevistados responderam de forma assertiva sobre a indicação para outros sujeitos.

Acerca da possível utilização para fins estéticos os resultados deste estudo apresentaram uma negativa por parte de $84 \%$ dos estudantes, desta forma este apresenta números similares ao encontrado por Silveira (2008) em que $90 \%$ dos entrevistados se puseram contra a utilização por questão estética.

Quando questionados sobre a abordagem do assunto em sala de aula os dados estão disponibilizados na Figura 6.

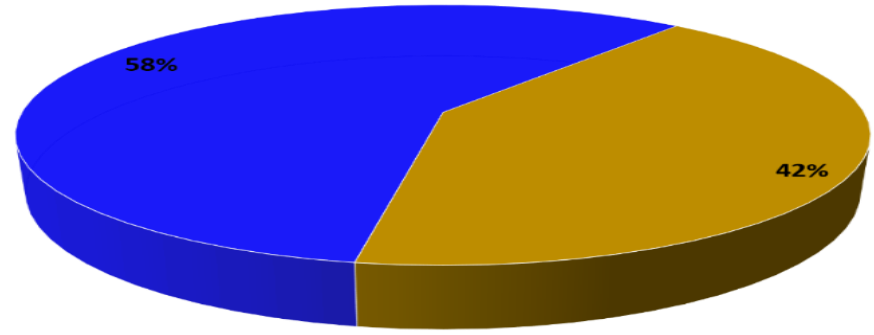

Fonte: Autores, 2020

Recebido em: 05/02/2021

Aceite em: 13/09/2021 
Figura 6 - Abordagem sobre o assunto em sala de aula.

No total da amostra colhida, 58\% relataram que houve a abordagem do assunto em sala de aula, resultado mais significativo foi encontrado no trabalho de Dias (2014) que $77 \%$ dos alunos responderam ter havido essa abordagem em sala de aula.

Na figura 7 observam-se as respostas referentes à importância da temática na grade curricular.
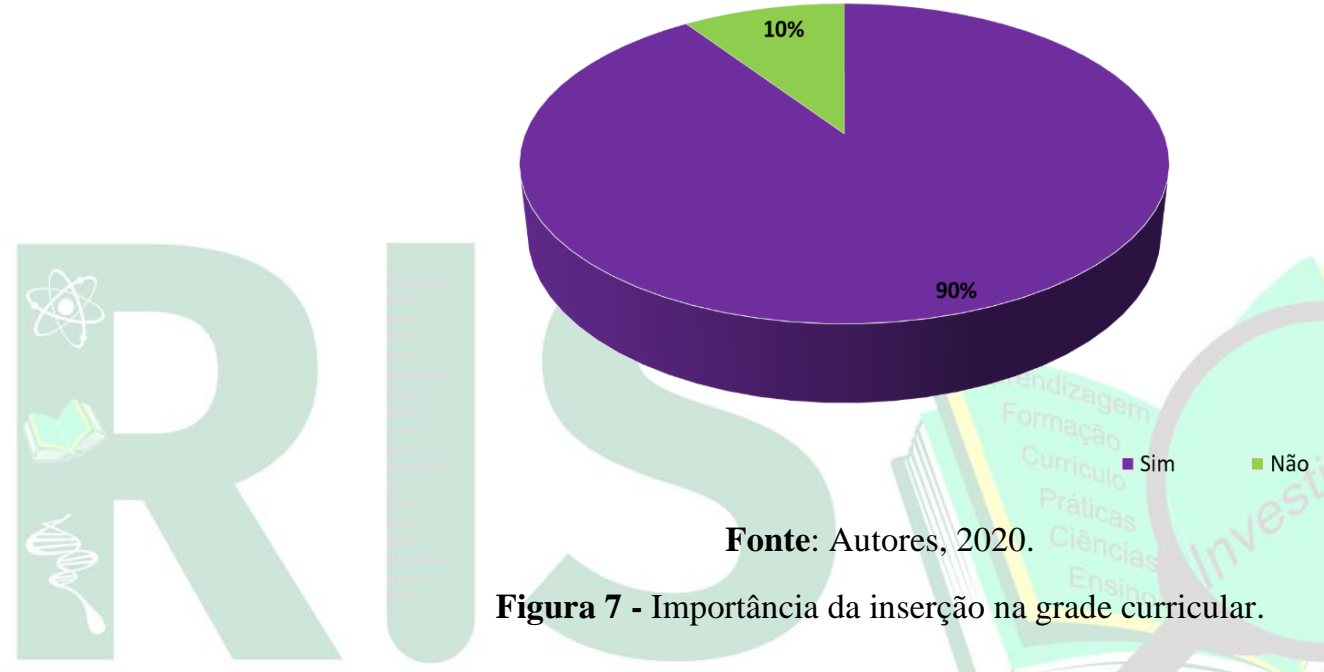

Fonte: Autores, 2020.

Figura 7 - Importância da inserção na grade curricular.

Nesse sentido os sujeitos da pesquisa afirmaram em sua maioria $(90 \%)$ que o tema deve ser abordado em sala de aula, $10 \%$ dos entrevistados não concordaram a abordagem do tema no âmbito escolar.

O presente levantamento corrobora com o estudo feito por Ferreira et al. (2010) com discentes de escolas públicas e privadas, neste a maioria dos entrevistados considerou que a escola tem um papel fundamental quanto a prevenção do uso de drogas.

Os participantes da pesquisa julgaram importante que a abordagem seja ampla e bem trabalhada nos currículos escolares. Em consonância, é relevante que os professores, mesmo com o tempo escasso e uma sobrecarga de trabalho, conseguem introduzir nas aulas conteúdos relacionados ao uso de anabolizantes. 


\section{CONCLUSÃO}

Concluiu-se a partir do presente estudo que o quantitativo de adolescentes que usaram EAA é baixo e que a maior parte desses já obtiveram informações a respeito dessas substâncias e que também conhecem os efeitos colaterais do seu consumo. Porém, o assunto para a maioria dos jovens não foi tratado em casa, o que aumenta a responsabilidade da escola em dedicar-se a essa abordagem.

A maioria dos entrevistados relatou não ter recebido a oferta para o uso e que também não indicaria o produto a ninguém. Para aquelas que já receberam a proposta para o uso dos EAA a maior parte foi abordada por amigos.

De acordo com o papel da escola os participantes destacaram a relevância da temática estar inserida nas aulas e na grade curricular. Tal fato pode ser realizado mediante a interdisciplinaridade. Nesse sentido fica evidente a necessidade de que a tratativa seja adequada e que o conhecimento sobre os EAAs possa ser significativo para o aluno.

\section{REFERÊNCIAS}

ANDRADE, F. S. C. et al. Concepções dos discentes do ensino médio da cidade de São João do rio do peixe sobre o uso de anabolizantes: $3^{\circ}$ CONEDU CONGRESSO

NACIONAL DE EDUCAÇÃO, Anais. São João do Rio do Peixe. Campina Grande: Realize. p. $01-07 ., 2016$.

ANJOS, S. C. Dos. Meios, estratégias e ações em abordagem interdisciplinar sobre suplementos alimentares e anabolizantes no ensino médio. 2014. 142f. Dissertação (mestrado). Universidade Federal de São João Del Rei. Faculdade de Educação. São João Del Rei - MG. 2014.

ARAÚJO, J. P. O uso de esteroides androgênicos anabolizantes entre estudantes do ensino médio no Distrito Federal. 2003. 90 f. Dissertação de mestrado Programa de (Pós-Graduação) em Educação Física). Universidade Católica de Brasília, Brasília. 2003.

ARMELIN, Maria. Genoveva. Prevenção às drogas na escola. O mundo da saúde, São Paulo, v. 23, n. 1, p. 48-52, 1999.

BOFF, Sérgio. Ricardo. Esteroides anabólicos e exercício: ação e efeitos colaterais. Revista Brasileira de Ciência e Movimento. v.18, n.1, p. 81-88. 2010.

Recebido em: 05/02/2021

Aceite em: 13/09/2021 
BRASIL. Ministério de Educação (MEC), Secretaria da Educação Média e Tecnológica (Semtec). PCN+ Ensino médio: Orientações educacionais complementares aos Parâmetros Curriculares Nacionais- Linguagens, Códigos e suas Tecnologias. Brasília: MEC/Semtec, 2002.

BRITO, Ariane de; FARO, André. Significações atribuídas aos anabolizantes: um embate entre o desejo e o risco. Psicologia, Saúde \& Doenças, v. 18, n. 1, p. 102-114, 2017.

CANO MT.; FERRERIANI, MGC.; MEDEIROS, M.; GOMES, R. - Auto-imagem na adolescência. Revista Eletrônica de Enfermagem [online]. v.

1, n.1, 1999.

CARREIRA FILHO, D. Prevalência do uso de substancias químicas com objetivo de modelagem corporal entre adolescentes de 14 a 18 anos, de ambos os sexos, do município de São Caetano do Sul, São Paulo, Brasil, 2003. 2005. 255p. Tese (doutorado) - Universidade Estadual de Campinas, Faculdade de Ciências Médicas, Campinas, SP. 2003.

CONFEF - Conselho Federal de Educação Física - Código de Ética do Profissional de Educação Física. Disponível em: https://www.confef.org.br/confef/resolucoes/381. Acesso em: 21 de fevereiro de 2017.

CONSELHO NACIONAL DE ANTIDOPAGEM - (CNAD). Dopagem no desporto. 2004. p. 11.

CANAVEZ, Márcia Figueira; ALVES, Alisson Rubson; CANAVEZ, Luciano Simões. Fatores predisponentes para o uso precoce de drogas por adolescentes. Cadernos unifoa, v. 5 , n. 14 , p. 57-63, 2017.

COSTA, Diene. Pires. Esteroides anabolizantes: uma visão dos alunos que cursam a $8^{\mathrm{a}}$ série. Movimentum: Revista Digital de Educação Física, Ipatinga, v.02, p. 01-14, ago. 2007.

CUNHA, Tatiane. Sousa et al. Esteroides anabólicos androgênicos e sua relação com a prática desportiva. Revista Brasileira de Ciências Farmacêuticas. [online].v.40, n.2, p.165-179. 2004.

DARIDO, S. C. Temas transversais e a educação física escolar. UNIVERSIDADE ESTADUAL PAULISTA. Caderno de formação: formação de professores didática dos conteúdos. São Paulo: Cultura Acadêmica, v. 6, p. 76-89, 2012.

DE SIQUEIRA NOGUEIRA, F. R. et al. Anabolic-androgenic steroid use among Brazilian bodybuilders. Substance use \& misuse, v. 49, n. 9, p. 1138-1145, 2014.

DIAS, I. H. P. Análise do conhecimento sobre esteroides anabólicos androgênicos entre estudantes e professores de escolas públicas do município de Corumbá - MS.

Recebido em: 05/02/2021

Aceite em: 13/09/2021 
Monografia (Graduação em Educação Física) Corumbá Ms 2014. Universidade Federal de Mato Grosso do Sul, 2014.

FERREIRA, T. C. D. et al. Percepções e atitudes de professores de escolas públicas e privadas perante o tema drogas. Interface Comunicação Saúde Educação, São Paulo, v. 14, n. 34, p.551-562, 2010.

FUMAGALLI, L.; SANTOS, T.; VARGAS, V.; ILHA, P. Conhecimentos e comportamentos relacionados à saúde de escolares. Revista Insignare Scientia - RIS, v. 2, n. 4, p. 100-118, 19 dez. 2019.

GONZAGA, J. P. Ensino, Saúde e Ambiente, conhecimento dos estudantes do ensino médio de Santana do Ipanema sobre os esteroides anabolizantes andrógenos. Santana do Ipanema, v. 5, n. 2, p.45-56, ago. 2012.

HALL, R. C.W.; HALL, R. C.W.; CHAPMAN, Marcia J. Psychiatric complications of anabolic steroid abuse. Psychosomatics, v. 46, n. 4, p. 285-290, 2005.

HARTGENS, Fred; KUIPERS, Harm. Effects of androgenic-anabolic steroids in athletes. Sports medicine, v. 34, n. 8, p. 513-554, 2004.

INÁCIO, F.R.; COSTA, C. R. C; BARROS, A. R. de.; GRANJEIRO, P. A.

Levantamento do uso de anabolizantes e suplementos nutricionais em academias de musculação. Movimento e Percepção, Espírito Santo do Pinhal, v. 9, n. 13, p.288-299, dez. 2008.

IRIART, J. A. B..; CHAVES, J. C.; ORLEANS, R. Ghignone de. Body cult and use of anabolic steroids by bodybuilders. Cadernos de saúde publica, v. 25, n. 4, p. 773-782, 2009.

MAHAN, L. Kathleen. Escott-Stump S. Krause's food, nutrition \& diet therapy. Philadelphia, W. B. Saunders Company, 1996.

MALBERGIER, A.; CARDOSO, L. R. D.; AMARAL, R. A. do. Uso de substâncias na adolescência e problemas familiares. Cadernos de Saúde Pública, v. 28, p. 678-688, 2012.

OLIVEIRA, U. de. O uso de esteroides androgênicos anabolizantes entre adolescentes e sua relação com a prática da musculação. 2012. 168 p. Tese (doutorado) - Universidade Estadual de Campinas, Faculdade de Ciências Médicas, Campinas, SP. 2012.

RIBEIRO, P. C. P. O uso indevido de substâncias: esteroides anabolizantes e energéticos. Adolesc Latinoam, v. 2, n. 2, p. 97-101, 2001.

RIBEIRO, P. C. P. Alerta: Os riscos dos esteroides anabolizantes. Boletim da Associação Mineira de Adolescência, Belo Horizonte, 1999.

Recebido em: 05/02/2021

Aceite em: 13/09/2021 
RIBEIRO, P. C. P. O uso indevido de substâncias: esteroides anabolizantes e energéticos. Adolesc Latinoam. v.2, n.2, p.97-101. 1999.

SANTOS, A. M. O Mundo Anabólico: análise do uso de esteroides anabólicos nos esportes. Barueri: Manole, 275 p. 2003.

SECRETARIA DE ESTADO DE EDUCAÇÃO DE MINAS GERAIS. Conteúdo Básico

Comum - Educação Física- Educação Básica - Ensino Médio (2005). Disponível em: http://crv.educacao.mg.gov.br/sistema_crv/index2.aspx??id_objeto=23967 Acesso 11 Nov. 2015.

SILVA, J. A. O papel do professor de educação física na prevenção ao uso de drogas pelos alunos do ensino fundamental. 2014. $47 \mathrm{f}$. Monografia - Curso de Licenciatura em Educação Física, Universidade de Brasília, Buritis, 2014.

SILVEIRA, T. R. P. O estudo de esteroides anabólicos-androgênicos no ensino médio: uma proposta metodológica. 2008. 42 f. TCC (Graduação) - Curso de Química, Centro Universitário La Salle - Unilasalle, Canoas, 2008.

SOCIEDADE BRASILEIRA DE ENDOCRINOLOGIA E METABOLOGIA (SBEM). 2016 Anabolizantes Esteroides e os Jovens. Disponível em: http://www.endocrino.org.br. Acesso em: 22 de abr. 2017.

SOUZA, E. S.; FISBERG, M. O uso de esteroides anabolizantes na adolescência. Brazilian Pediatric News, v. 4, n. 1, p. 2002, 2002.

OSORIO VELOSO, L.; SOARES, R.; COPETTI, J. A relação da afetividade professor/aluno no processo de ensino-aprendizagem. Revista Insignare Scientia RIS, v. 3, n. 5, p. 60-76, 18 dez. 2020.

URTADO, C. B. Prevalência e perfil da utilização de esteróides anabolizantes por praticantes de treinamento de força com idade entre 14 e 24 anos na cidade de Piracicaba, São Paulo, Brasil. 2014. 75 f. Tese (doutorado) - Universidade Estadual de Campinas, Faculdade de Ciências Médicas, Campinas, SP. 2014.

VARELLA, D. Abuso de anabolizantes. Disponível em: <http://www.drauziovarella. com.br/artigos/anabolizantes (2011).asp. Acesso em: 13 de abr. 2017.

Recebido em: 05/02/2021

Aceite em: 13/09/2021 